\title{
IUGR is Commonly Observed among Prenatally Diagnosed Chromosome 4p Deletion Syndrome
}

\author{
Su J S", Chan YM"\#, Cao Y ${ }^{2,3 \#, ~ Y a n g ~ S H}{ }^{4}$, Luo J S', \\ Qin Z1, Zhu XF', Fu HY ${ }^{5}$, Huang HQ ${ }^{1}$, Zhang $Y^{1}$, \\ Zhang SJ ${ }^{1}$, Lu WL ${ }^{1}$, Li W' ${ }^{1}$, J iang TT ${ }^{1}$, Wei SK ${ }^{1}$, \\ Leung TY', ${ }^{2,6}$ Choy KW ${ }^{1,2,6 *}$ and Wei HW ${ }^{1 *}$ \\ ${ }^{1}$ Department of Genetic and Metabolic Central \\ Laboratory, Guangxi Maternal and Child Health Hospital, \\ China \\ ${ }^{2}$ Department of Obstetrics \& Gynecology, The Chinese \\ University of Hong Kong, China \\ ${ }^{3}$ Department of Pediatrics, The Chinese University of \\ Hong Kong, China \\ ${ }^{4}$ Department of Ultrasound Examination, Guangxi \\ Maternal and Child Health Hospital, China \\ ${ }^{5}$ Department of Prepotency Out-Patient Clinic, Guangxi \\ Maternal and Child Health Hospital, China \\ ${ }^{6}$ Chinese University of Hong Kong-Baylor College of \\ Medicine J oint Center for Medical Genetics, The Chinese \\ University of Hong Kong, China \\ \#These authors contributed equally to this work \\ *Correspondling author: Wei Hongwei, Guangxi \\ Zhuang Autonomous Region Women and Children \\ Health Care Hospital, NO.225, Xinyang Road, Nanning \\ City, Guangxi province, 530012, People's Republic of \\ China
}

Choy Kwong Wai, Department of Obstetrics \& Gynecology, The Chinese University of Hong Kong, Hong Kong SAR, China

Received: J anuary 25, 2021; Accepted: February 27, 2021; Published: March 06, 2021

\author{
Abstract \\ Objective: our study aimed at retrospectively assessing the abnormal \\ prenatal ultrasound findings of chromosome $4 p$ deletion syndrome.
}

Methods: 21 cases with abnormal sonographic signs revealed $4 p$ deletion by Chromosome Microarray (CMA) in this retrospective analysis. Clinical information and molecular basis of this cohort were compared with those from other two groups in China, the critical region related to special ultrasound findings was mapped with the smallest regions of overlap.

Results: This is the largest prenatal series to evaluate the prenatal ultrasound features of $4 p$ deletion syndrome detected by CMA. Firstly we refined the relationship between the genomic coordinates with IUGR in chromosome $4 p$ terminal deletion syndrome. Additional chromosomal abnormalities was identified in 12 cases. Intrauterine embryonic arrest was diagnosed at first trimester for 9 cases. The most consistent ultrasound indicator was IUGR $(95.5 \%)$, and the smallest region response for IUGR correspond to a $2.05 \mathrm{Mb}$ at 4p16.3-pter (chr4: 68,345-2,121,057, hg19). Increased Nuchal Translucency (NT) could be a risk factor for predicting WHS at first-trimester pregnancy with the rate of $16.6 \%$ from our data. A $3.6 \mathrm{Mb}$ microdeletion located at $4 \mathrm{p} 16.3-$ pter (chr4: $68,345-3,753,422$, hg19) might be the candidate region associated with increased NT.

Conclusion: We identified IUGR as the most common feature in prenatal $4 p$ terminal deletion and Wolf-Hirschhorn syndrome. The existence of additional CNVs may contribution to possible explanations for the clinical heterogeneity of this syndrome. Prenatal findings of IUGR, increased NT or early spontaneous abortion should warrant the diagnosis of $4 p$ terminal deletion WHS.

Keywords: IUGR; Prenatal diagnosis; $4 p$ deletion syndrome; Chromosome microarray

\section{Introduction}

Wolf-Hirschhorn Syndrome (WHS; OMIM\#194190) is a wellknown contiguous gene deletion syndrome caused by chromosome $4 \mathrm{p}$ terminal deletion, first reported by Wolf and Hirschhorn in 1965 $[1,2]$. The prevalence was reported as 1 in 50,000 to 1 in 20,000 world widely and the female to male ratio was estimated to be 2:1 [3-5]. Distinctive craniofacial features of WHS patients are characterized as "Greek warrior helmet", including the wide bridge of the nose continuing to the forehead, high anterior hairline with prominent glabella, widely spaced eyes, epicanthus, highly arched eyebrows, short philtrum, downturned corners of the mouth, micrognathia, poorly formed ears with pits/tags, and microcephaly. Major structural anomalies such as renal hypoplasia, cardiac malformations, fetal growth retardation, and increased Nuchal Translucency (NT) are also reported in some of the WHS fetuses [6,7].

About $55 \%$ of WHS is caused by an isolated $4 p$ terminal deletion, and $40 \%-45 \%$ is due to an unbalanced translocation with a $4 \mathrm{p}$ deletion and a duplication of another chromosome. Such unbalanced translocations can be de novo or inherited from a parent-carrier of the balanced rearrangement. Other rare complex conditions include chromosome 4 ring, $4 \mathrm{p}$ deletion mosaicism, or a derivative chromosome 4 leading to 4 p16.3 deletion [8]. Conventional karyotyping analysis can detect $50-60 \%$ of WHS cases with deletions larger than $5 \mathrm{Mb}$. FISH analysis with WHSCR (WHS critical region) probe or Chromosomal Microarray (CMA) could detects more that $95 \%$ of deletions in WHS [9].

Two critical regions contributed the core phenotype of WHS, namely WHSCR and WHSCR2. The WHSCR was a $165 \mathrm{~kb}$ interval at $4 \mathrm{p} 16.3$, about $2 \mathrm{Mb}$ away from the chromosome 4 telomere [10], defined between the loci D4S166 and D4S3327 [10,11]. WHSCR2, partially overlaps with WHSCR [12], was mapped within a 300$600 \mathrm{~kb}$ region in $4 \mathrm{p} 16.3$, resides $1.9 \mathrm{Mb}$ from the terminal of the $4 \mathrm{p}$, between loci D4S3327 and D4S98-D4S168 [5]. Information on genotype-phenotype correlation for WHS is limited.

Prenatal ultrasound provides the opportunity to diagnose WHS prenatally. However, specific ultrasound markers has not been established for WHS. The most consistent presentation was severe IUGR [6,7], other signs such as increased NT, prominent glabella, ocular hypertelorism, micrognathia, short philtrum, cleft lip/palate, cystic cerebral lesions, abnormal nasal bone or renal hypoplasia were previously reported in cases of WHS diagnosed prenatally $[13,14]$. As the implementation of chromosomal microarray using in both
Austin J Obstet Gynecol - Volume 8 Issue 2 - 2021

Submit your Manuscript | www.austinpublishinggroup.com

Wei et al. () All rights are reserved
Citation: Su JS, Chan YM, Cao Y, Yang SH, Luo JS, Qin Z, et al. IUGR is Commonly Observed among Prenatally Diagnosed Chromosome 4p Deletion Syndrome. Austin J Obstet Gynecol. 2021; 8(2): 1169. 


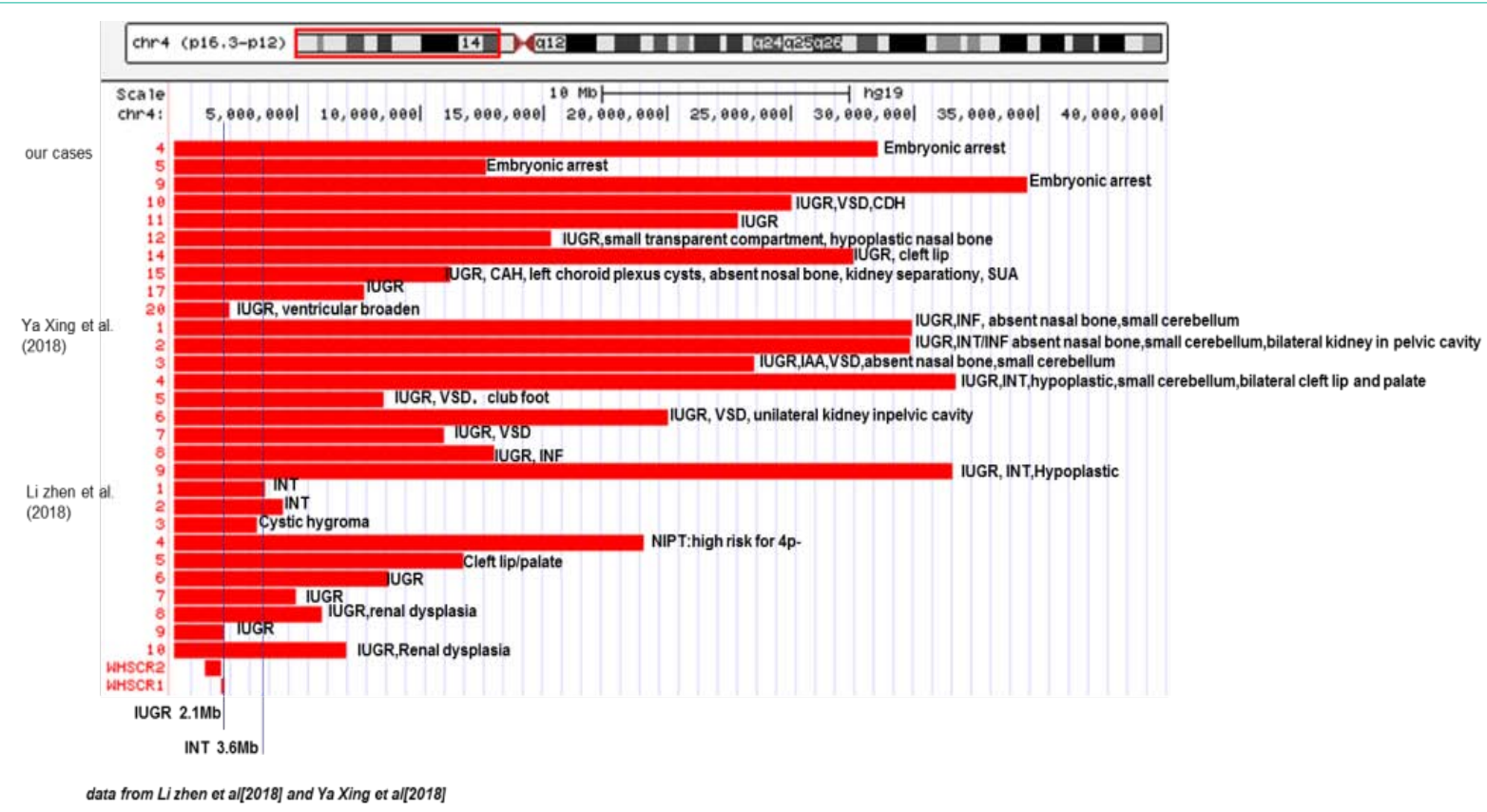

Figure 1: The summarization of isolated $4 p$ deletion cases from the literatures and our cohort with genomic coordinations and ultrasound findings.

postnatal and prenatal diagnosis of WHS, the critical regions for specific WHS features could probably be refined. Herein, we identified 21 prenatal cases with chromosome $4 \mathrm{p}$ terminal deletion detected by SNP-microarray by our retrospective study, we evaluated the deletion coordinates through reviewing the literature to refine the critical regions for IUGR and increased NT thickness by smallest regions pf overlap, and help further delineated the genotype-phenotype correlation in WHS with the specific prenatal ultrasound signs.

\section{Materials and Methods}

\section{Subjects}

This was a retrospective study to assess the clinical details of prenatal cases with $4 \mathrm{p}$ deletions Indications for prenatal invasive testings, prenatal ultrasound findings, CMA results and pregnancy outcome of these cases were reviewed. Overall, a total of 26,179 pregnant women were referred to our laboratory for invasive prenatal diagnosis from January 2013 to August 2018. The indications for invasive prenatal diagnosis include: fetus with various ultrasound abnormalities, embryonic arrest, intrauterine growth restriction (Head circumference/Abdominal Circumference/Biparietal Diameter $<-2 \mathrm{SD}$ ), cleft lip/palate, cystic cerebral lesions, abnormal nasal bone or renal hypoplasia, increased NT (thickness $>3$ millimeters), positive Down syndrome screening test, positive NIPT, family history with recurrent spontaneous miscarriage. Twenty-one cases with $4 \mathrm{p}$-deletions were recruited in this study.

\section{Prenatal ultrasound detection}

Fetal ultrasound anatomy scans were routinely performed for pregnant women by experienced sonographers using GE E8 ultrasound machines (General Electric Healthcare, US) in Maternal and Child Health Hospital of Guangxi Autonomous Region. Transabdominal ultrasound examination included a full structural survey, and NT was measured according to established guidelines during the gestational week $11^{\text {th }}$ to $13^{\text {th }}$.

\section{Molecular and cytogenetic analysis}

Chorionic villi sampling, amniocentesis or cordocentesis was performed under ultrasound guidance after informed consent. Genomic DNA was extracted using QIAamp DNA Blood Mini Kit (Qiagen, Germany) according to the manufacturer's protocol. SNP microarray testing was performed using Illumina HumanCytoSNP-12 v2.1 BeadChip (Illumina, USA). The SNP data were collected and analyzed by Illumina Genome Studio and KaryoStudio software. The coordinates were shown according to the human (GRCh37/hg19) assembly. The genomic critical regions for WHS related ultrasound abnormalities was proposed as according to the smallest regions of overlap based on the previously reported prenatal WHS cases and our WHS cohort.

\section{Results}

A total of 21 prenatal cases with $4 \mathrm{p}$ deletion were identified in our cohort. All of them were diagnosed prenatally by CMA, and twelve of them cases were also detected by karyotyping. Their detailed information were listed in (Table 1). Nine cases (42\%) were referred to the hospital for first trimester ultrasound test for suspected early spontaneous abortion, the median maternal age was 29 years old (23-44) and the median gestational age at prenatal diagnosis was 27 weeks (11-34). Case 1-3, 6-8, 13, 16, 18-19, 21 with additional pathogenic chromosome abnormalities. Two cases with an increased NT thickness (case 7, case 19) carried additional chromosome $7 \mathrm{p}$ terminal duplication. In total, 10 cases $(47 \%)$ were observed to have abnormal fetal ultrasound findings at second trimester of pregnancy.

Deletion sizes ranged from $5 \mathrm{Mb}$ to $35 \mathrm{Mb}$, and all included WHS critical regions WHSCR and WHSCR2 (Figure 1). Two cases (cases 5, 6) with sole $4 p$ terminal deletion resulted in sporadic abortion in early pregnancy. The smallest region relating to IUGR was located in the 
Table 1: Pathogenic copy number variants identified by CMA among our patients with chromosome $4 \mathrm{p}$ terminal deletion.

\begin{tabular}{|c|c|c|c|c|c|c|c|c|}
\hline Case & $\begin{array}{c}\text { Maternal } \\
\text { age (years) }\end{array}$ & $\begin{array}{c}\text { Gestation } \\
\text { (weeks+ } \\
\text { days) }\end{array}$ & $\begin{array}{l}\text { Pregnancy } \\
\text { history }\end{array}$ & SNP array(hg19) & Inheritance & G-band & $\begin{array}{l}\text { Ultrasound } \\
\text { finding }\end{array}$ & $\begin{array}{l}\text { Pregnancy } \\
\text { outcomes }\end{array}$ \\
\hline 1 & 29 & NA & G2P0 & $\begin{array}{c}\text { arr4p16.3p16.1(48,283-7,142,868) } \\
\text { x1, 14q31. } \\
\text { 1q32.33(80,848,449-107,282,437) } \\
\text { x3 }\end{array}$ & $\begin{array}{l}\text { Maternal, 46,XX,t(4;14) } \\
\quad(\mathrm{p} 16.1 ; \mathrm{q} 31.1)\end{array}$ & NA & EA & SA \\
\hline 2 & 26 & NA & G2P0 & $\begin{array}{c}\text { arr4p16. } \\
3 p 15.33(48,283-11,547,106) \\
\times 1,15 q 21 . \\
3 q 26.3(56,821,025-102,397,836) \times 3\end{array}$ & $\begin{array}{l}\text { Maternal, 46,XX,t(4;15) } \\
\quad(\mathrm{p} 16 ; \mathrm{q} 22)\end{array}$ & NA & EA & SA \\
\hline 3 & 31 & $8+4$ & G1P0 & $\begin{array}{c}\text { arr4p15.3 } \\
1 \mathrm{p} 16.3(48,283-18,787,232) \times 1,4 \mathrm{p} 1 \\
5.1 \mathrm{p} 15.31(18,789,372-27,878,240) \\
\mathrm{x} 1 \sim 2,4 \mathrm{q} 34 \\
3 \mathrm{q} 35.2(179,929,126-190,880,409) \\
\mathrm{x} 1 \sim 2\end{array}$ & NA & NA & EA & SA \\
\hline 4 & 34 & $8+2$ & G2P0 & $\begin{array}{c}\text { arr4p16.3p15.1(48,283 } \\
-28,544,298) \times 1\end{array}$ & NA & NA & EA & SA \\
\hline 5 & 36 & $9+1$ & G2P1 & $\begin{array}{c}\operatorname{arr} 4 \mathrm{p} 15.3 \\
3 \mathrm{p} 16.3(48,283-12,707,180) \times 1\end{array}$ & NA & NA & EA & SA \\
\hline 7 & 38 & $11+6$ & G3P1 & $\begin{array}{c}\text { arr4p16.3(48,283-3,804,286)x1, } \\
7 \mathrm{p} 22.3 p 22.1(46,239-6,779,270) \times 3\end{array}$ & NA & NA & $\mathrm{NT}: 3.8 \mathrm{~mm}$ & SA \\
\hline 8 & 28 & $12+1$ & G4P0 & $\begin{array}{c}\text { arr4p16.3p16.1(48,283-8,728,783) } \\
\times 1,4 q 35.2(188,609,718- \\
190,880,409) \times 1,10 q 11.2 \\
2 q 11.23(46,947,635-51,739,867) \times 1 \\
8 p 23.3 p 23.1(176,818-11,898,209) \\
\times 3\end{array}$ & NA & NA & EA & SA \\
\hline 9 & 23 & $8+1$ & GOPO & $\begin{array}{c}\operatorname{arr} 4 p 15.1 p 16.3(48,283-34,573,079) \\
x 1\end{array}$ & NA & NA & EA & SA \\
\hline 10 & 28 & $22+6$ & G1P1 & $\begin{array}{c}\operatorname{arr} 4 p 16.3 p 15.2(48,283-25,065,147) \\
x 1\end{array}$ & NA & $46, \mathrm{XN}, \mathrm{del}(4)(\mathrm{p} 15)$ & IUGR,VSD,CDH & TOP \\
\hline 11 & 30 & $23+1$ & G2P1 & $\begin{array}{c}\operatorname{arr} 4 p 16.3 p 15.2(48,283-22,878,904) \\
x 1\end{array}$ & de novo & $46, \mathrm{XX}, \mathrm{del}(4)(\mathrm{p} 15)$ & IUGR & TOP \\
\hline 12 & 28 & $24+4$ & G2P0 & $\begin{array}{c}\text { arr4p16. } \\
\text { 3p15.32(48283-15,315,490)x1 }\end{array}$ & NA & $46, \mathrm{XX}, \mathrm{del}(4)(\mathrm{p} 15)$ & IUGR,STC,HNB & TOP \\
\hline 13 & 27 & 25 & G2P1 & $\begin{array}{c}\text { arr4p16.3p16.1(48,283 -8,728,783) } \\
x 1\end{array}$ & NA & $46, X Y$ & FGR & TOP \\
\hline 15 & 23 & $28+2$ & G1P0 & $\begin{array}{c}\operatorname{arr} 4 p 16.3 p 16.1(48,283-11,236,408) \\
x 1\end{array}$ & NA & 46,XX,del(4)(p16.1p16.3) & $\begin{array}{c}\text { CAH, CPC, } \\
\text { HNB,RH, SUA }\end{array}$ & TOP \\
\hline 16 & 28 & 30 & G1P0 & $\begin{array}{c}\text { arr4p16.3p16.1(48,283-7,048,842) } \\
\text { x1, arr4p16. } \\
1 \mathrm{p} 13(7,055,603-43,968,054) \times 3\end{array}$ & de novo & $\begin{array}{c}46, X Y, \operatorname{der}(4) \operatorname{del}(4)(p 16) \operatorname{dup}(4) \\
(\mathrm{p} 13 p 16)\end{array}$ & $\begin{array}{l}\text { IUGR,Cleft } \\
\text { lip,VB,RH }\end{array}$ & TOP \\
\hline 17 & 26 & $31+6$ & G1P0 & $\begin{array}{c}\operatorname{arr} 4 p 16.3 p 16.1(48,283-7,782,434) \\
x 1\end{array}$ & NA & $46, X Y, \operatorname{del}(4)(\mathrm{p} 16)$ & IUGR & TOP \\
\hline 18 & 28 & 32 & G1P0 & $\begin{array}{c}\text { arr4p16.3p15.1(48,283-34,397,464) } \\
\text { x1, 21q11. } \\
2 q 21.1(14,687,571-20,989,949) \times 1\end{array}$ & de novo & $45, \mathrm{XN}, \operatorname{der}(4) \mathrm{t}(4 ; 21)(\mathrm{p} 15 ; \mathrm{q} 21),-21$ & $\begin{array}{l}\text { IUGR,RH, } \\
\text { Microcephaly }\end{array}$ & TOP \\
\hline 19 & 32 & $12+2$ & G3P1 & $\begin{array}{c}\text { arr4p16.3(48,283-3,350,248)x1, } \\
7 \mathrm{p} 15.3 \mathrm{p} 22.3(46,239-22,584,183) \times 3\end{array}$ & $\begin{array}{l}\text { Maternal } 46, X X, t(4,7) \\
(p 16, p 15)\end{array}$ & $46, X X, \operatorname{der}(4) t(4,7)(p 16, p 15)$ & $\mathrm{NT}: 4.1 \mathrm{~mm}$ & TOP \\
\hline 20 & 35 & $24+3$ & G3P1 & arr4p16.3(48,283-2,300,841)x1 & NA & normal & IUGR,VB & TOP \\
\hline 21 & 28 & $16+3$ & $\mathrm{G} 2$ & $\begin{array}{c}\text { arr4p16.3(63,781-3,809,371)x1, } \\
\text { 11p15.5p15.4(215,049-3,381,999) } \\
\text { x3 }\end{array}$ & $\begin{array}{l}\text { Maternal 46,XX.isht }(4,11) \\
\quad(\mathrm{p} 16.3, \mathrm{p} 15)\end{array}$ & NA & NA & TOP \\
\hline
\end{tabular}

IUGR: Intrauterine Growth Restriction; SA: Spontaneous Abortion; EA: Embryonic Arrest; CDH: Congenital Diaphragmatic Hernia; STC: Small Transparent Compartment; HNB: Hypoplastic Nasal Bone; CAH: Cerebellar Axillary Hypoplasia; CPC: Choroid Plexus Cysts; RH: Renal Hypoplasia; SUA: Single Umbilical Artery; VB: Ventricular Broaden; NT/INF: Nuchal translucency/Fold; NA: Not Available.

band 4p16.3, contained the WHSCR and WHSCR2, approximately $2.05 \mathrm{Mb}$ from the telomere, described by Zhen et al. (Figure 1). Increased NT/NF thickness was counted to $18.7 \%$ in the cases with pure $4 \mathrm{p}$ deletion and the region was narrowed down within a $3.6 \mathrm{Mb}$ interval in 4p16.3 (Figure 1).

\section{Discussion}

Our study provided the largest series of prenatal WHS cases to assess the relationship between ultrasound abnormalities and their molecular defects. The incidence of $4 \mathrm{p}$ deletion in our cohort was one in $1250(21 / 26,179)$. Among them, $47.6 \%(10 / 21)$ of our cases had an isolated $4 \mathrm{p}$ terminal deletion, while $38.0 \%(8 / 21)$ of our cases had a de novo or familial inherited unbalanced rearrangement, characterized by a deletion of $4 \mathrm{p}$ and a partial trisomy of another chromosome as reported before $[15,16]$. Since most of the previously reported prenatal WHS cases were identified by conventional karyotyping with a $4 \mathrm{p}$ deletion larger than $5 \mathrm{Mb}$, it is difficult to precisely refine the critical regions for specific ultrasound anomaly $[1,2,10,11,13,14,17$ 24]. Refining with the two prenatal centers that include diagnosis of WHS with CMA as stated in supplemental Table S1, we are able 
Table 2: Summary of the WHS fetuses with pure terminal $4 p$ deletion from the literature compared to the cases in our cohort.

\begin{tabular}{|c|c|c|c|}
\hline Prenatal Ultrasound Signs & Previously reported $(n=61)^{a}$ & Our group $(n=21)$ & Total \\
\hline Embryonic Arrest & Not mentioned & $8 / 21(36.3 \%)$ & $8 / 21(36.3 \%)$ \\
\hline IUGR ${ }^{b}$ & $55 / 56(98.5 \%)$ & $10 / 12^{\mathrm{c}}(83.3 \%)$ & $65 / 68(95.5 \%)$ \\
\hline Typical"Greek warrior helmet" facial appearance & $10 / 40(27.5 \%)$ & $0 / 12$ & $10 / 58(17.2 \%)$ \\
\hline prominent glabella & 2 & - & - \\
\hline short philtrum & 1 & - & - \\
\hline micrognathia & 5 & 2 & - \\
\hline hypertelorism & 6 & - & - \\
\hline flat profile & 2 & - & - \\
\hline Renal hypoplasia & $5 / 56(8.9 \%)$ & $3 / 12(25.0 \%)$ & 8/68 (11.7\%) \\
\hline Cardiac malformation & $7 / 56(12.5 \%)$ & $1 / 12(8.3 \%)$ & $8 / 68(11.7 \%)$ \\
\hline Cleft lip and palate & $3 / 56(5.3 \%)$ & $2 / 12(16.6 \%)$ & $5 / 68(7.3 \%)$ \\
\hline Increased NT/NF & $11 / 56(19.6 \%)$ & $2 / 12(16.6 \%)$ & $13 / 68(19.1 \%)$ \\
\hline Absent/hypoplastic nasal bone & $6 / 56(10.7 \%)$ & $2 / 12(16.6 \%)$ & 8/68 (11.7\%) \\
\hline
\end{tabular}

aData collected from Xing $Y$, et al. [6] and Zhen L, et al. [7].

bIUGR was defined as $\mathrm{HC} / \mathrm{AC} / \mathrm{BPD}<-2$ standard deviation.

c 8 cases in our cohort presented embryonic arrest, and cases 21 were diagnosed with WHS using non-invasive prenatal testing without other detail ultrasound signs, thus the denominator decreased from 21 to 12.

to include more cases to refine the genotype-phenotype correlation of prenatal WHS. Through our observation, the most consistent ultrasound sign of prenatal WHS cases was IUGR (95.5\%) (Table 2). Using overlapping analyses of $4 \mathrm{p}$ terminal deletions, we concluded a smallest region spanned from 4 p16.3 to the telomere including WHSCR and WHSCR 2 of $2.05 \mathrm{Mb}$ in size to be associated with severe IUGR, described by Li zhen et al. [7]. Similarly, 4p16.34 pter of about $3.6 \mathrm{Mb}$ in size (chr4: 68,345-3,753,422, hg19, case10) might be the candidate region associated with increased NT (Figure 1). Both regions echoed the findings reported by $\mathrm{Li}$ et al., Wright et al., Zollino et al. proposed the critical region known as WHSCR and WHSCR2 by smallest regions of overlap $[5,10]$. Through the same strategy, we first refined the smallest region account for the distinctive IUGR and increased NT in prenatal WHS in China based on the CMA results. Notably, the phenotypic spectrum of postnatal WHS cases were classified into three categories based on the deletion size: (1) individuals with a deletion smaller than $3.5 \mathrm{Mb}$ at $4 \mathrm{p} 16-4$ pter usually present with mild phenotype; (2) individuals with a deletion between 5 and $18 \mathrm{Mb}$ usually presents with classic WHS phenotype; (3) individuals with a deletion larger than $22 \mathrm{Mb}$ usually present with major malformations [12]. Variable expressivity of clinical features also indicated that WHS was a contiguous gene syndrome $[3,25]$. The postnatal classification may not apply for prenatally diagnosed cases, as the phenotype-genotype correlation had not been well established during the first and second trimester. Most cases of $4 \mathrm{p}$ terminal deletion in our cohort or in other reported cases only presented with IUGR. Embryonic arrest occurred at first-trimester pregnancy with 4 pter deletion had not been described before, the rate was $42.8 \%(9 / 21)$ in our cohort. Three cases with isolated 4 pter deletion, and the remaining 6 cases had additional pathogenic chromosomal abnormalities which may contribute the clinical outcome. CMA for case 6 identified a complex rearrangement with terminal $4 \mathrm{p}$ and $4 \mathrm{q}$ deletion simultaneously likely resulting from a chromosome 4 ring. However, karyotype was not available to confirm the findings. CMA of case 7 with spontaneous miscarriage showed a 4p16.3 deletion and a 7p22.3p22.1 duplication. This finding raised the suspicion of parental balanced translocation. However, couple refused further evaluation. Our findings supported that important gene or genes within $4 \mathrm{p}$ terminal region is potentially responsible to regulate embryonic development. CMA is not a routine practice for pregnancies with early embryonic arrest, our findings support that CMA should be performed to look for submicroscopic chromosomal abnormalities in these cases.

Increased NT $(>3 \mathrm{~mm})$ or NF $(>6 \mathrm{~mm})$ thickness was another risk factor for WHS at first-trimester pregnancy. The rate of increased NT in WHS cases was $16.6 \%(2 / 12)$ which is comparable to previous report of $19 \%$ [6]. Case 31 were diagnosed with WHS by non-invasive prenatal testing (NIPT) with a large chromosome $4 \mathrm{p}$ deletion in the first trimester. Accuracy of NIPT on the detection of microdeletion syndrome is determined by the size thus many cases of WHS with small deletion (<3-5 megabase) would be missed by NIPT. Also, due to the low prevalence of WHS in the population, clinical application of NIPT on WHS is limited by a low positive predictive value [26]. Based on the findings of our cohort and previous reports, NT assessment might be more useful in detecting WHS in the first trimester comparing to NIPT.

IUGR was the most common ultrasound finding in prenatal WHS cases. The previously reported rate was $98.2 \%(55 / 56)[6,7]$, compared with $83.3 \%(10 / 12)$ in our cohort . Generally, the IUGR was observed by ultrasound at second trimester fetal structure evaluations, even early at $16^{\text {th }}$ gestational week. The IUGR could be also various degree? and severe (all measurements were below the third percentile) in cases at the third trimester [27]. In our cohort, 7 cases were diagnosed with IUGR less than one percentile. The size of chromosome $4 \mathrm{p}$ deletion does not necessarily correlate with the severity of IUGR. For example, case 18 presented with severe IUGR (below $1^{\text {st }}$ centile) with the CMA findings of $2.05 \mathrm{Mb}$ microdeletion at 4p16.3. While case 11 presented with IUGR below $3^{\text {rd }}$ centile had the chromosome findings of a much larger deletion of $15.2 \mathrm{Mb}$ at $4 \mathrm{p} 16.3$ - 
4p16.1. In our cohort, we demonstrated that structural anomaly of WHS such as renal hypoplasia, cardiac anomaly, cleft lip and palate could be detected prenatally by USG. Although typical WHS facial characteristics was previously reported to be detectable prenatally, it would be difficult in prenatal USG and depend on the sonographer to detect subtle facial features $[6,7,22,25,28]$. Our study and prenatal ultrasound findings reiterate the clinical utility of CMA for fetuses with structural anomaly.

\section{Conclusion}

We presented the largest prenatal series of WHS diagnosed by CMA. IUGR was the most common features in prenatal WHS cases and the smallest region of overlap on chromosome $4 \mathrm{p}$ relating to IUGR was approximately $2.05 \mathrm{Mb}$ in size, span $4 \mathrm{p} 16.3$ to the telomere including WHSCR1 and WHSCR2. Embryonic arrest could occur in the cases with $4 \mathrm{p}$ terminal deletion. We also proposed the smallest deletion region relating to increased NT may be a $3.6 \mathrm{Mb}$ interval at 4 p16.3-4pter. The rate of increased NT/NF thickness in WHS cases was $16.6 \%$ from our own data, which showed that increased NT/NF thickness is a strong indicator for WHS diagnosis. Prenatal CMA should be considered for pregnancies with isolated or multiple anomaly such as renal hypoplasia, cardiac malformation, cleft lip and palate, skeletal anomalies, absent/hypoplastic nasal bone to look for WHS.

\section{Acknowledgment}

We appreciate the patients and family for the study. This work was supported by the China NSFC project 81741009 and Guangxi Zhuang Region Health Department No. Z20200623.

\section{References}

1. Hirschhorn K, Cooper HL, Firschein IL. Deletion of short arms of chromosome 4-5 in a child with defects of midline fusion. Humangenetik. 1965; 1: 479-482.

2. Wolf $U$, Reinwein $H$, Porsch R, Schroter R, Baitsch $H$. [Deficiency on the short arms of a chromosome No. 4]. Humangenetik. 1965; 1: 397-413.

3. Wieczorek D, Krause M, Majewski F, Albrecht B, Horn D, Riess O, et al Effect of the size of the deletion and clinical manifestation in Wolf-Hirschhorn syndrome: analysis of 13 patients with a de novo deletion. European journal of human genetics: EJHG. 2000; 8: 519-526.

4. Zollino M, Di Stefano C, Zampino G, Mastroiacovo P, Wright TJ, Sorge G, et al. Genotype-phenotype correlations and clinical diagnostic criteria in WolfHirschhorn syndrome. American journal of medical genetics. 2000; 94: 254 261.

5. Zollino M, Lecce R, Fischetto R, Murdolo M, Faravelli F, Selicorni A, et al Mapping the Wolf-Hirschhorn syndrome phenotype outside the currently accepted WHS critical region and defining a new critical region, WHSCR-2. American journal of human genetics. 2003; 72: 590-597.

6. Xing Y, Holder JL, Liu Y, Yuan M, Sun Q, Qu X, et al. Prenatal diagnosis of Wolf-Hirschhorn syndrome: from ultrasound findings, diagnostic technology to genetic counseling. Archives of gynecology and obstetrics. 2018; 298: 289295.

7. Zhen L, Fan SS, Huang LY, Pan M, Han J, Yang X, et al. Prenatal diagnosis of Wolf-Hirschhorn syndrome: Ultrasonography and molecular karyotyping results. European journal of obstetrics, gynecology, and reproductive biology. 2018; 225: 19-21.

8. South ST, Hannes F, Fisch GS, Vermeesch JR, Zollino M. Pathogenic significance of deletions distal to the currently described Wolf-Hirschhorn syndrome critical regions on $4 \mathrm{p} 16.3$. American journal of medical genetics Part C, Seminars in medical genetics. 2008; 148C: 270-274.
9. Battaglia A, Carey JC, Wright TJ. Wolf-Hirschhorn (4p-) syndrome. Advances in pediatrics. 2001; 48: 75-113.

10. Wright TJ, Ricke DO, Denison K, Abmayr S, Cotter PD, Hirschhorn K, et al. A transcript map of the newly defined $165 \mathrm{~kb}$ Wolf-Hirschhorn syndrome critical region. Human molecular genetics. 1997; 6: 317-324.

11. Wright TJ, Costa JL, Naranjo C, Francis-West P, Altherr MR. Comparative analysis of a novel gene from the Wolf-Hirschhorn/Pitt-Rogers-Danks syndrome critical region. Genomics. 1999; 59: 203-212.

12. Zollino M, Murdolo M, Marangi G, Pecile V, Galasso C, Mazzanti L, et al. On the nosology and pathogenesis of Wolf-Hirschhorn syndrome: genotypephenotype correlation analysis of 80 patients and literature review. American journal of medical genetics Part C, Seminars in medical genetics. 2008; 148C: $257-269$

13. Boog G, Le Vaillant C, Collet M, Dupre PF, Parent P, Bongain A, et al. Prenatal sonographic patterns in six cases of Wolf-Hirschhorn (4p-) syndrome. Fetal diagnosis and therapy. 2004; 19: 421-430.

14. Sase M, Hasegawa K, Honda R, Sumie M, Nakata M, Sugino N, et al. Ultrasonographic findings of facial dysmorphism in Wolf-Hirschhorn syndrome. American journal of perinatology. 2005; 22: 99-102.

15. Dallapiccola B, Mandich P, Bellone E, Selicorni A, Mokin V, Ajmar F, et al. Parental origin of chromosome $4 p$ deletion in Wolf-Hirschhorn syndrome. American journal of medical genetics. 1993; 47: 921-924.

16. Battaglia A, Carey JC, South ST. Wolf-Hirschhorn syndrome: A review and update. American journal of medical genetics Part C, Seminars in medical genetics. 2015; 169: 216-223.

17. Eiben B, Leipoldt M, Schubbe I, Ulbrich R, Hansmann I. Partial deletion of $4 p$ in fetal cells not present in chorionic villi. Clinical genetics. 1988; 33: 49-52.

18. Verloes A, Schaaps JP, Herens C, Soyeur D, Hustin J, Dodinval P. Prenatal diagnosis of cystic hygroma and chorioangioma in the Wolf-Hirschhorn syndrome. Prenatal diagnosis. 1991; 11: 129-132.

19. Tachdjian G, Fondacci C, Tapia S, Huten Y, Blot P, Nessmann C. The WolfHirschhorn syndrome in fetuses. Clinical genetics. 1992; 42: 281-287.

20. Vinals F, Sepulveda W, Selman E. Prenatal detection of congenital hypospadias in the Wolf-Hirschhorn (4p-) syndrome. Prenatal diagnosis. 1994; 14: 1166-1169.

21. Kohlschmidt N, Zielinski J, Brude E, Schafer D, Olert J, Hallermann C, et al. Prenatal diagnosis of a fetus with a cryptic translocation $4 p ; 18 p$ and WolfHirschhorn syndrome (WHS). Prenatal diagnosis. 2000; 20: 152-155.

22. Chen CP, Hsu CY, Lee CC, Chen WL, Chen LF, Wang W. Prenatal diagnosis of de novo pure partial monosomy $4 p(4 p 15.1-->p t e r)$ in a growth-restricted fetus with a Greek warrior helmet face and unilateral facial cleft on threedimensional ultrasound. Prenatal diagnosis. 2004; 24: 934-936.

23. Levaillant JM, Touboul C, Sinico M, Vergnaud A, Serero S, Druart L, et al. Prenatal forehead edema in $4 \mathrm{p}$ - deletion: the 'Greek warrior helmet' profile revisited. Prenatal diagnosis. 2005; 25: 1150-1155.

24. Casaccia G, Mobili L, Braguglia A, Santoro F, Bagolan P. Distal 4p microdeletion in a case of Wolf-Hirschhorn syndrome with congenital diaphragmatic hernia. Birth defects research Part A, Clinical and molecular teratology. 2006; 76: 210-213.

25. Sifakis S, Manolakos E, Vetro A, Kappou D, Peitsidis P, Kontodiou M, et al. Prenatal diagnosis of Wolf-Hirschhorn syndrome confirmed by comparative genomic hybridization array: report of two cases and review of the literature. Molecular cytogenetics. 2012; 5: 12.

26. Advani HV, Barrett AN, Evans MI, Choolani M. Challenges in non-invasive prenatal screening for sub-chromosomal copy number variations using cellfree DNA. Prenatal diagnosis. 2017; 37: 1067-1075.

27. De Keersmaecker B, Albert M, Hillion Y, Ville $Y$. Prenatal diagnosis of brain abnormalities in Wolf-Hirschhorn (4p-) syndrome. Prenatal diagnosis. 2002; 22: 366-370. 
28. Ikonomou T, Antsaklis P, Daskalakis G, Sindos M, Papantoniou N, Kosmaidou $Z$, et al. Prenatal diagnosis of Wolf-Hirschhorn syndrome: ultrasonography and genetics. The journal of maternal-fetal \& neonatal medicine: the official journal of the European Association of Perinatal Medicine, the Federation of Asia and Oceania Perinatal Societies, the International Society of Perinatal Obstet. 2013; 26: 941-942. 